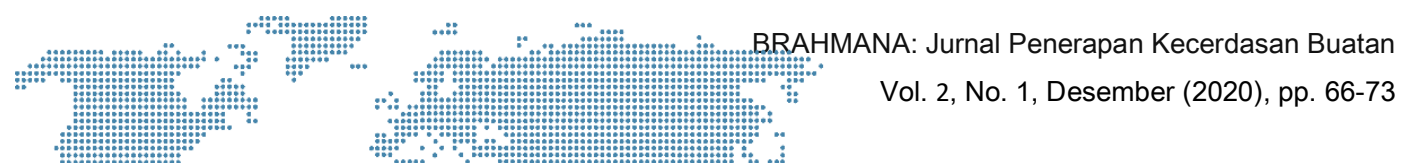

\title{
Penerapan Metode ELECIRE Dalam Pemilihan Masker Wajah Tenbaik Untuk Berbagai Jenis Kulit
}

\author{
要

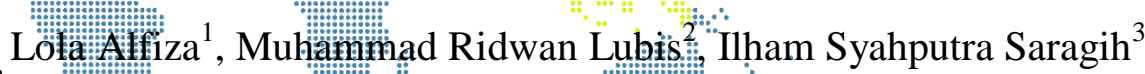 \\ ${ }^{1,3}$ STIKOM Tunas Bämg sä, Pematangșticntum, Sumatera Utara, Indonesia \\ ${ }^{2}$ AMIIK Tunas Bangsa, Pematangsiantar, S.umatera Utara, Indonesia \\ Jln." Sudirman Blok A No. 1-3 Pematangsiantar, Sumatera Utara \\ ${ }^{1}$ lolaalfizaa@gmail.com, ${ }^{2}$ ridwanlubis@amiktunasbangsa.ac.id, \\ ${ }^{3}$ ilhamsyahputra@stikomtunasbangsa.ac.id
}

\begin{abstract}
The research aims to make the Decision Support System the best means of choosing masks with various types of facial skin especially Indonesian women, then recommending which masks are best to use. This problem can be ranked in the study. The method used in this research is the Electre method on the Decision Support System. Sources of research data obtained by interview and observation by giving a set of questions or statements to the customer used as respondents to be answered. The selection of face masks is used with several criteria including: (K1) oily skin, (K2) acne prone skin, (K3) dull skin, (K4) normal skin. And has sub criteria: color (c1), Texture (c2), Aroma (c3), Price (c4). The results of the research using the Electre method are expected to make it easier to determine the ranking of data winners from each alternative by the assessment process and facilitate system implementation.
\end{abstract}

Keywords : Decision Support System, MCDM, Electre Method, Website Based Application, Face Mask

\begin{abstract}
Abstrak
Penelitian bertujuan untuk menjadikan Sistem Pendukung Keputusan menjadi sarana terbaik dalam memilih masker dengan berbagai jenis kulit wajah khususnya wanita Indonesia, kemudian merekomendasikan masker mana yang baik digunakan. Masalah ini dapat dijadikan perangkingan dalam penelitian tersebut. Metode yang digunakan pada penelitian adalah metode Electre pada Sistem Pendukung Keputusan dengan menggunakan aplikasi berbasis website untuk mencari masker wajah wanita Indonesia. masker wajah Sumber data penelitian diperoleh dengan cara wawancara dan observasi dengan memberikan seperangkat pertanyaan atau pernyataan kepada costumer yang dijadikan responden untuk dijawab. Pemilihan masker wajah digunakan dengan beberapa kriteria antara lain : (K1) kulit berminyak, (K2) kulit berjerawat, (K3) kulit kusam, (K4) kulit normal. Dan memiliki sub criteria : warna(c1), Tekstur(c2), Aroma(c3), Harga(c4). Hasil penelitian menggunakan metode Electre diharapkan dapat memudahkan dalam menentukan peringkat pemenang data dari setiap alternatif dengan proses penilaian serta memudahkan implementasi sistem.
\end{abstract}

Kata Kunci : Sistem Pendukung Keputusan, MCDM, Metode Electre, Aplikasi Berbasis Website, Masker Wajah

\section{Pendahuluan}

Memiliki penampilan menarik serta wajah yang cantik merupakan hal yang diidamkan oleh setiap manusia. Namun, penampilan yang menarik bukan hanya dilihat dari pakaian dan segala aksesoris yang dipakainya, melaikan ditunjang dengan adanya kulit yang sehat. Kulit merupakan bagian paling penting yang harus dirawat dan dijaga. Saat ini banyak produk kecantikkan yang ditawarkan kepada masyarakat salah satunya yaitu masker wajah. 


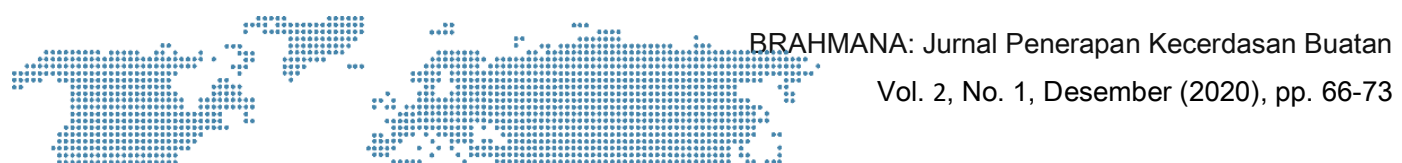

Masker wajah meruphan masker kecantukan yang berbentuk seperti gel pasta dan

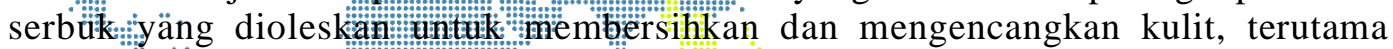
kulit wajalo Contohnya seperti maskể Wa jah untuk jenis külit berminyak, berjerawat, kering

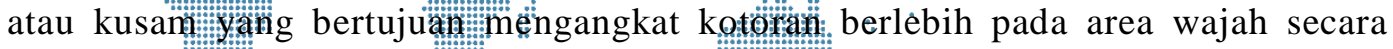
menyeluruh: : Sebelum mélakukan perawatan mengetahui ïjenis kulit wajah kita masing-masing: "Jenis kulit wajah yang umum dimiliki oleh manusia yaitu kulit wajah normal, berminyak, dan kering [1].

Timbulnya masalah kulit wajah bisa disebabkan oleh faktor penggunaan produk masker kecantikan yang mengandung bahan berbahaya untuk kulit wajah karena banayak orang tidak berhati-hati dalam memilih masker terutama remaja ataupun masyarakat. Mengingat banyak faktor yang dapat mengakibatkan kulit bermasalah, maka untuk merawat dan mengatasi kulit penulis menggunakan SPK dalam menyelesaikan permasalahan perangkingan dengan metode ELECTRE karena SPK banyak memecahkan masalah didunia nyata dan menunjukkan kinerja yang baik [2] yang bertujuan untuk memudahkan bagi pihak manajemen perusahaan produck kecantikan agar dapat mengetahui secara rinci tentang pemilihan masker wajah yang baik untuk berbagai jenis kulit.

Kelebihan dari metode electre kasus-kasus yang memiliki banyak alternatife dalam pemilihan. Dengan diterapkannya metode electre dalam penelitian ini diharapkan dapat membantu masyarakat agar lebih berhati-hati dalam memilih masker wajah yang baik digunakan sesuai jenis kulit masing-masing. Penelitian ini juga diharapkan dapat Menambah pengetahuan, wawasan, dan pengalaman dalam mengembangkan dan mengabdikan diri dalam dunia kesehatan khususnya di Bidang kecantikan dimasa yang akan datang.

\section{Metodologi Penelitian}

\subsection{Masker Wajah}

Masker wajah merupakan masker kecantikan yang berbentuk seperti gel pasta dan serbuk yang dioleskan untuk membersihkan dan mengencangkan kulit, terutama kulit wajah. Melakukan perawatan sangat diperlukan untuk menjaga kesehatan kulit dan mengembalikan kelembapan kulit menjadi halus dan bersih. Ragam masker wajah tergantung pada jenis dan masalah kulit. Contohnya seperti masker wajah untuk jenis kulit berminyak, berjerawat, kasar atau kusam yang bertujuan mengangkat kotoran berlebih pada area wajah secara menyeluruh [3].

\subsection{Sistem Pendukung Keputusan}

Sistem Pendukung Keputusan (DSS) merupakan suatu pemodelan pengambilan keputusan dimana untuk memecahkan suatu permasalahan sebagai sistem komputer yang akan mengolah data menjadi sebuah informasi untuk pemilihan yang didasarkan kriteria tertentu atas dua atau lebih alternatife dalam situasi semi terstruktur dan tidak terstruktur [4][5].

\subsection{Metode Electre}

Electree merupakan salah satu metode pengambilan keputusan yang multikriteria berdasarkan pada konsep outrangking dengan menggunakan perbandingan berpasangan dari alternatife-alternatif berdasarkan setiap kriteria yang sesuai. Metode Electre digunakan pada kondisi dimana alternatif yang kurang sesuai dengan kriteria akan dieliminasi, dan alternatif yang sesuai dapat dihasilkan, dengan kata lain Metode Electre digunkan pada kondisi dimana alternatif yang sesuai dapat dihasilkan. Jadi, Electre digunkan untuk kasus -kasus dengan banyak alternatif namun hanya sedikit kriteria yang dilibatkan[6].

Langkah-langkah yang digunakan dalam Metode Electre adalah sebagai berikut: 


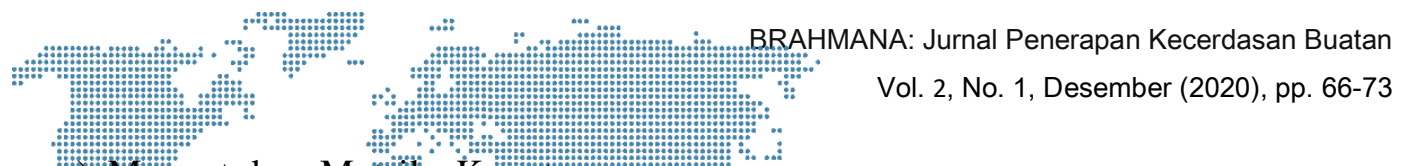

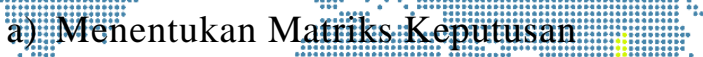

Páda kolom-kojom yang:

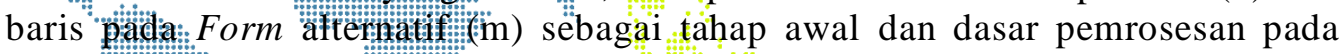

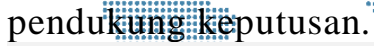

$\mathrm{X}=\left[\begin{array}{ccccc}x_{11} & x_{12} & x_{13} & \ldots & x_{1 n} \\ x_{21} & x_{22} & x_{23} & \ldots & x_{2 n} \\ \ldots & \ldots & \ldots & \ldots & \ldots \\ x_{m 1} & x_{m 2} & x_{m 3} & \ldots & x_{m n}\end{array}\right]$

b) Normalisasi matriks keputusan

Dalam prosedur ini, setiap atribut diubah menjadi nilai comparable. Setiap normalisasi dari nilai xij dapat dilakukan dengan rumus:

$r_{i j}=\frac{x_{i j}}{\sqrt{\sum_{i=1}^{m} x_{i j}{ }^{2}}}$

Sehingga didapat matriks $\mathrm{R}$ hasil normalisasi,

$\mathrm{R}=\left[\begin{array}{ccccc}r_{11} & r_{12} & r_{13} & \ldots & r_{1 n} \\ r_{21} & r_{22} & r_{23} & \ldots & r_{2 n} \\ \ldots & \ldots & \ldots & \ldots & \ldots \\ r_{m 1} & r_{m 2} & r_{m 3} & \ldots & r_{m n}\end{array}\right]$

c) Pemberian Nilai Bobot

Keterangan selanjutnya, pembuat keputusan menyediakan factor minat (bobot) pada setiap kriteria yang menyatakan nilai kepentingan relatif $\left(\mathrm{W}_{\mathrm{j}}\right)$.

$$
\begin{aligned}
& W=\left(W_{1}, W_{2}, \ldots, W_{n}\right) ; \\
& \sum_{j=1}^{n} W_{j}=1
\end{aligned}
$$

d) Menghitung Matriks Bobot Ternormalisasi

Setiap kolom pada matriks $\mathrm{R}$ dikalikan dengan bobot $\left(\mathrm{W}_{\mathrm{j}}\right)$ yang ditentukan oleh pembuat keputusan dapat dilihat dibawah ini.

$V_{i j}=W_{i} R_{i j}$

Dimana $\mathrm{V}$ adalah

$$
v_{i j}=\left[\begin{array}{lllll}
v_{11} & v_{12} & v_{13} & \ldots & v_{1 n} \\
v_{21} & v_{22} & v_{23} & \ldots & v_{2 n} \\
\cdot & \cdot & \cdot & \ldots & \cdot \\
v_{m 1} & v_{m 2} & v_{m 3} & \ldots & v_{m n}
\end{array}\right]
$$

e) Menentukan Himpunan Concordancedan Discordance

Himpunan concordance $\left\{\mathrm{C}_{\mathrm{k} l}\right\}$ menyatakan bahwa hitungan criteria bobot $\mathrm{A}_{\mathrm{k}}$ dengan kemungkinan lain lebih baik daripada $\mathrm{A}_{1}$.

$C_{k l}=\left\{j \mid V_{k j} \geq V_{l j}\right\} \quad$ dengan $\mathrm{j}=1,2, \ldots, \mathrm{n}$

Himpunan discordance $\left\{\mathrm{D}_{\mathrm{k} 1}\right\}$ tertulis sebagai berikut :

$D_{k l}=\left\{j \mid V_{k j}<V_{l j}\right\} \quad$ dengan $\mathrm{j}=1,2, \ldots, \mathrm{n}$

f) Menghitung Matriks Concordance dan Discordance

Untuk menghitung atau menentukan matriks corcodance adalah engan cara menambah bobot yang terdapat dalam matriks corcodance.

$$
C_{k l}=\sum_{j \in C_{k l}} W_{j}
$$

Untuk menentukan matriks discordance adalah dengan membagi selisih maksimum kriteria yang dimasukkan kedalam himpunan discordance dengan selisih tertinggi diantara nilai-nilai yang ada pada semua kriteria.

$$
D_{k l}=\frac{\max \left\{\left|V_{k j}-V_{l j}\right|\right\} \quad j \in D_{k l}}{\max \left\{\left|V_{k j}-V_{l j}\right|\right\} \quad V_{j}}
$$

Matriks D juga hasil $\mathrm{m} \times \mathrm{m}$ dan tidak mengambil nilai kolom $1 \mathrm{dan}$ baris $\mathrm{k}$, array d sebagai berikut.

$$
d_{i j=} \quad\left[\begin{array}{llll}
- & d_{12} & \ldots & d_{1 n}
\end{array}\right]
$$




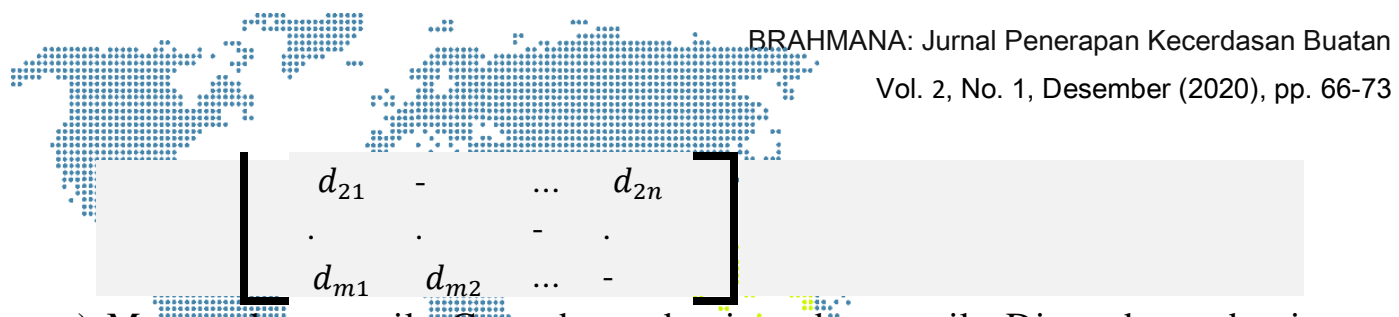

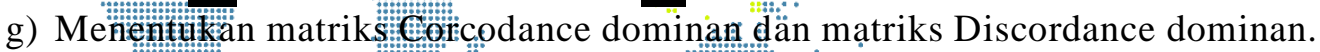
Array in in dapat menobentuk nilai anbourog: atas (threshold) $\underline{C}$. Rumus yang dapat yang dapat menghasilkan nilai $C$.

$$
\underline{C}=\frac{\sum_{k=1}^{m} \sum_{l=1}^{m} C_{k l}}{m(m-1)}
$$

Alternative $A_{k}$ dapat memiliki kesempatan untuk mendominasi $A_{1}$ jika indeks konkordansi $\mathrm{C}_{\mathrm{kl}}$ melebihi nilai ambang atas $\underline{\mathrm{C}}$ dengan $\mathrm{C}_{\mathrm{kl}} \geq \underline{\mathrm{C}}$ dan elemen dominan $\mathrm{F}$ matriks corcodance didefenisikan sebagai:

$$
F_{k l}=\left\{\frac{1, \text { jika } C_{k l} \geq \underline{C}}{0, \text { jika } C_{k l}<\underline{C}}\right.
$$

Hal yang sama juga dilakukan kepada matriks dominan matriks diskordansi $G$ dengan nilai ambang atas $\underline{D}$. Rumus berikut dapat memberikan nilai $\mathrm{D}$ :

$$
\underline{D}=\frac{\sum_{k=1}^{m} \sum_{l=1}^{m} D_{k l}}{m(m-1)}
$$

Elemen dominan $\mathrm{G}$ matriks diskordansi ditetapkan sebagai:

$$
G_{k l}=\left\{\begin{array}{l}
\frac{1, \text { jika } D_{k l} \geq \underline{D}}{0, \text { jika } D_{k l}<\underline{D}}
\end{array}\right.
$$

h) Menentukan Matriks Dominan Keseluruhan

Model E sebagai total matrik dominan adalah matriks dimana setiap elemen dikalikan diantara elemen matriks $\mathrm{F}$ dan bentuk persamaan elemen $\mathrm{G}$.

$$
E_{k l}=F_{k l} * G_{k l}
$$

i) Eliminasi Alternatif yang Kurang Baik

Matriks E memberikan hasil yang lebih baik pada setiap pilihan alternatif, contohnya ketika $E_{k l}=1$ maka alternative $A_{k}$ lebih baik dari pada alternatif $A_{l}$. Mengindikasikan baris di dalam matriks $\mathrm{E}$ yang memiliki nilai total sedikitnya $\mathrm{E}_{\mathrm{kl}}=1$ dapat dieliminasi

\section{Hasil dan Pembahasan}

Dalam penelitian ini data yang digunakan akan diolah dari hasil kuisioner, yang diberikan kepada konsumen dari beberapa 5 tokoh kosmetik kecantikan Pematangsiantar. Penulis memberikan kuisioner kepada konsumen dengan jumlah 30 sampel data masing-masing 1 toko 6 kuesioner. Pada penelitian ini digunakan 5 kriteria dalam melakukan perangkingan masker wajah terbaik untuk berbagai jebnis kulit sebagai berikut : Berminyak (C1), Berjerawat (C2), Kering (C3), dan Normal (C4) dan terdapat 4 subkriteria dari masing-masing kriteria yaitu sebagai berikut: Warna, Tekstur, Aroma, dan Harga. Setelah data alternatif diketahui, maka selanjutnya dilakukan penilaian hasil kuisioner untuk setiap alternatif sesuai dengan kriteria. Hasil rata rata Penilaian kuisioner seperti pada tabel 1 berikut:

Tabel 1. Tabel Penilaian Alternatif

\begin{tabular}{|c|c|c|c|c|}
\hline \multirow{2}{*}{ Alternatif } & \multicolumn{5}{|c|}{ Kriteria } \\
\cline { 2 - 5 } & Berminyak & Berjerawat & Kusam & Normal \\
\hline WD & 3 & 2 & 4 & 4 \\
\hline EM & 3 & 4 & 3 & 2 \\
\hline SP & 4 & 3 & 3 & 2 \\
\hline GR & 4 & 3 & 4 & 2 \\
\hline MR & 4 & 4 & 3 & 2 \\
\hline
\end{tabular}




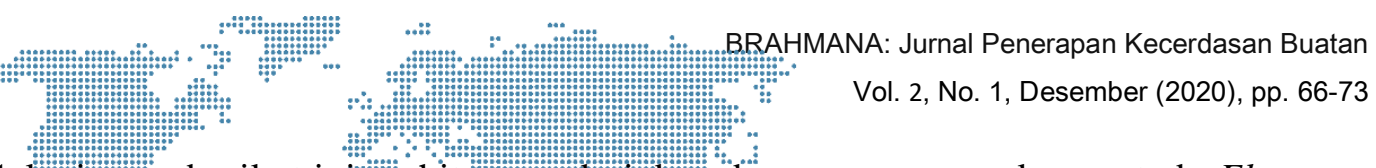

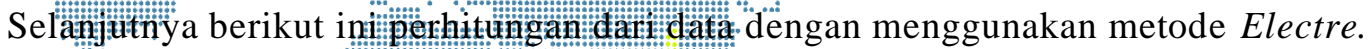

1) Meruentukan Matrilks Keputisan:

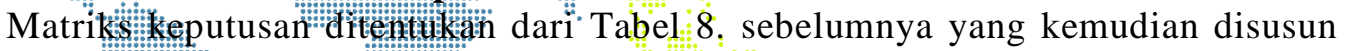
kedalam matums keputusan menggunakan persảmaan (1). Sehingga didapatlah

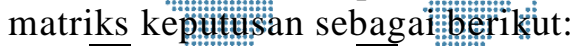

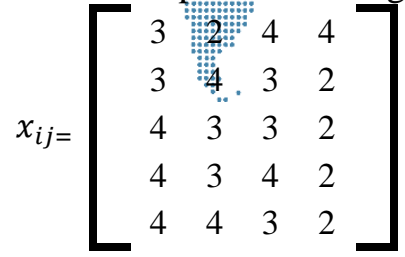

2) Normalisasi Matriks Keputusan

$\left|\mathrm{x}_{1}\right|=\sqrt{3^{2}+3^{2}+4^{2}+4^{2}+4^{2}}=\sqrt{66}=8,124$

$\mathrm{r}_{11}=\frac{x_{11}}{\left|x_{1}\right|}=\frac{3}{8,124}=0,369$

$\mathrm{r}_{21}=\frac{x_{21}}{\left|x_{1}\right|}=\frac{3}{8,124}=0,369$

$\mathrm{r}_{31}=\frac{x_{31}}{\left|x_{1}\right|}=\frac{4}{8,124}=0,492$

$\mathrm{r}_{41}=\frac{x_{41}}{\left|x_{1}\right|}=\frac{4}{8,124}=0,492$

$\mathrm{r}_{51}=\frac{x_{51}}{\left|x_{1}\right|}=\frac{4}{8,124}=0,492$

...

$\left|\mathrm{x}_{4}\right|=\sqrt{4^{2}+2^{2}+2^{2}+2^{2}+2^{2}}=\sqrt{32}=5,656$

$\mathrm{r}_{14}=\frac{x_{14}}{\left|x_{4}\right|}=\frac{4}{5,656}=0,707$

$\mathrm{r}_{24}=\frac{x_{24}}{\left|x_{4}\right|}=\frac{2}{5,656}=0,353$

Sehingga didapat matriks $\mathrm{R}$ sebagai berikut:

$R_{i j}=\left[\begin{array}{llll}0,369 & 0.272 & 0,52 & 0,707 \\ 0,369 & 0,544 & 0,39 & 0,353 \\ 0,492 & 0,408 & 0,39 & 0,353 \\ 0,492 & 0,408 & 0,52 & 0,353 \\ 0,492 & 0,544 & 0,39 & 0,353\end{array}\right]$

3) Pembobotan pada matriks yang telah dinormalisasi

$\mathrm{V}_{11}=5 * 0,369=1,845 \mathrm{~V}_{12}=4 * 0,272=1,088$

$\mathrm{V}_{21}=5 * 0,369=1,845 \mathrm{~V}_{22}=4 * 0,544=2,176$

$\cdots$

$\mathrm{V}_{53}=3 * 0,39=1,17 \quad \mathrm{~V}_{54}=2 * 0,353=0,706$

Setelah semua dihitung maka didapat hasil:

$v_{i j}=\left[\begin{array}{llll}1,845 & 1,088 & 1,56 & 1,414 \\ 1,845 & 2,176 & 1,17 & 0,706 \\ 2,46 & 1,632 & 1,17 & 0,706 \\ 2,46 & 1,632 & 1,56 & 0,706 \\ 2,46 & 2,176 & 1,17 & 0,706\end{array}\right]$

4) Menentukan himpunan Concordance dan Discordance

$C_{21}$

If $j=1 \rightarrow v_{21} \geq \mathrm{v}_{11} \rightarrow 1,845 \geq 1,845 \rightarrow=$ yes then $j=1$

If $j=2 \rightarrow \mathrm{v}_{22} \geq \mathrm{v}_{12} \rightarrow 2,176 \geq 1,088 \rightarrow$ yes then $j=2$

If $j=3 \rightarrow \mathrm{v}_{23} \geq \mathrm{v}_{13} \rightarrow 1,17 \geq 1,56 \rightarrow=$ no

If $j=4 \rightarrow \mathrm{v}_{24} \geq \mathrm{v}_{14} \rightarrow 0,706 \geq 1,414 \rightarrow=$ no

Hasil $\mathrm{C}_{21}=\{1,2\}$

$\ddot{c}$

$C_{52}$ 

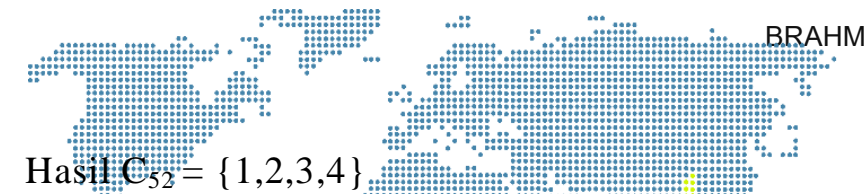

Vol. 2, No.

$\mathrm{Hasime(C_{52 } =}=\{1,2,3,4\}$

Sehingga hasil dari himpunate concondance adalah

$\mathrm{C}_{21}=\{1,2$

$\mathrm{C}_{31}=\{1,2\}$

$\mathrm{C}_{41}=\{1,2,3\}$

$\mathrm{C}_{45}=\{1,3,4\}$

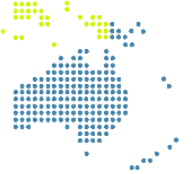

Sehingga hasil dari discordance sebagai berikut:

$\mathrm{D}_{21}=\{3,4\}$

$\mathrm{D}_{31}=\{3,4\}$

$\mathrm{D}_{41}=\{4\}$

$\mathrm{D}_{45}=\{2\}$

5) Menghitung Matriks Concordance dan Discordance

$\mathrm{C}_{21}=\mathrm{w} 2+\mathrm{w} 3+\mathrm{w} 4=2+3+4=9$

$\mathrm{C}_{31}=\mathrm{w} 2+\mathrm{w} 3=2+3=5$

$\mathrm{C}_{45}=\mathrm{w} 1+\mathrm{w} 3+\mathrm{w} 5=2+3+5=11$

Hasil perhitungan diatas disusun menjadi sebuah matriks concordance sebagai berikut:

$$
C_{k l}=\left[\begin{array}{lllll}
- & 10 & 5 & 5 & 5 \\
9 & - & 9 & 6 & 9 \\
12 & 10 & - & 11 & 10 \\
9 & 10 & 14 & - & 10 \\
9 & 14 & 14 & 11 & -
\end{array}\right]
$$

Untuk menentukan matriks discordance adalah dengan membagi selisih maksimum kriteria yang dimasukkan kedalam himpunan discordance dengan selisih tertinggi diantara nilai nilai yang ada pada semua kriteria.

$$
\begin{aligned}
& v_{i j}=\left[\begin{array}{llll}
1,845 & 1,088 & 1,56 & 1,414 \\
1,845 & 2,176 & 1,17 & 0,706 \\
2,46 & 1,632 & 1,17 & 0,706 \\
2,46 & 1,632 & 1,56 & 0,706 \\
2,46 & 2,176 & 1,17 & 0,706
\end{array}\right] \\
& \mathrm{D}_{21}=\frac{\max \{|2,176-1,088| ;|1,17-1,56| ;|0,706-1,414|\}}{\max \{|2,176-1,088| ;|1,17-1,56| ;|0,706-1,414|\}} \\
& \mathrm{D}_{21}=\frac{\max \{1,088 ; 0,39 ; 0,708\}}{\max \{1,088 ; 0,39 ; 0,708\}} \\
& \mathrm{D}_{21}=\frac{1,088}{1,088} \\
& \mathrm{D}_{21}=1 \\
& \mathrm{D}_{51}=\frac{1,088}{1,088} \\
& \begin{aligned}
& d_{i j 1}=\left[\begin{array}{rrrrr}
- & 1 & 0 & 0 & 0 \\
0 & - & 0 & 0 & 0 \\
0 & 1 & - & 1 & 1 \\
1 & 1 & 1 & - & 1 \\
0 & 1 & 1 & 1 & -
\end{array}\right] \\
& 0,1304+0+0,0652+0+1+0+0+0+1+1+0,9644+1+1+1+1+1+ \\
& 1+1+0+0,1304
\end{aligned}
\end{aligned}
$$




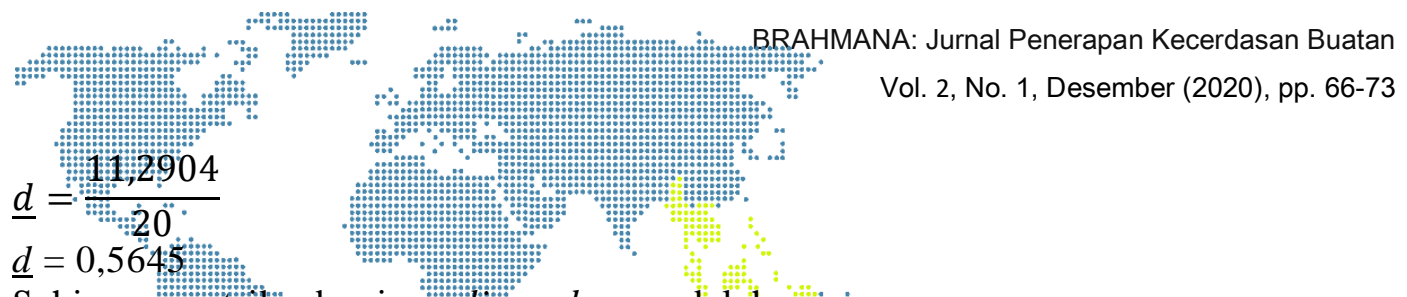

Sehingga matumes dominä mescordance adalah

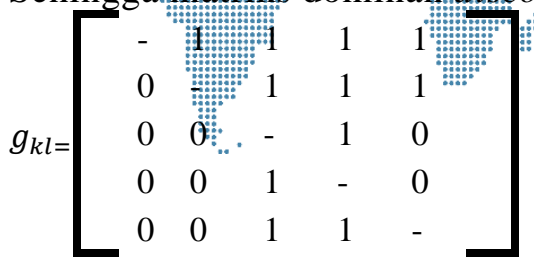

6) Menentukan matriks concordane dominaan dan matriks discordance dominan.
$9+9+12+9+5+10+10+14+5+9+14+14+5+6+14+$
$\underline{c}=\frac{14+5+9+5+10}{5(5-1)}$
$\underline{c}=\frac{192}{20}=9,6$

Sehingga matriks dominan concordance adalah

$f_{k l}=\left[\begin{array}{ccccc}- & 1 & 1 & 1 & 1 \\ 0 & - & 1 & 1 & 0 \\ 0 & 0 & - & 1 & 0 \\ 0 & 0 & 0 & - & 0 \\ 0 & 0 & 1 & 1 & -\end{array}\right]$

matriks dominan disconcordance adalah

$f_{k l}=\left[\begin{array}{ccccc}- & 1 & 1 & 1 & 1 \\ 0 & - & 1 & 1 & 1 \\ 1 & 1 & - & 1 & 1 \\ 1 & 1 & 0 & - & 1 \\ 0 & 0 & 0 & 0 & -\end{array}\right]$

7) Menentukan matriks dominan keseluruhan

$\mathrm{E}_{21}=\mathrm{F}_{21} * \mathrm{G}_{21}=0 * 0=0$

$\mathrm{E}_{31}=\mathrm{F}_{31} * \mathrm{G}_{31}=0 * 1=0$

$\mathrm{E}_{41}=\mathrm{F}_{41} * \mathrm{G}_{41}=0 * 1=0$

$\cdots$

$\mathrm{E}_{45}=\mathrm{F}_{45} * \mathrm{G}_{45}=0 * 1=0$

8) Eliminasi Alternatif yang Kurang Baik

$E_{k l}=\left[\begin{array}{ccccc}- & 1 & 0 & 0 & 0 \\ 0 & - & 0 & 0 & 0 \\ 0 & 1 & - & 1 & 1 \\ 1 & 1 & 0 & - & 1 \\ 0 & 0 & 0 & 0 & -\end{array}\right]$

Berdasarkan hasil akhir yang diperoleh, maka didapat alternatif $A_{1}$ dengan nilai $E_{k l}$ $=1$, alternatif $A_{2}$ dengan nilai $E_{k l}=0$, alternatif $A_{3}$ dengan nilai $E_{k l}=3$, alternatif $A_{4}$ dengan nilai $E_{k l}=3$, alternatif $A_{5}$ dengan nilai $E_{k l}=0$. Sehingga masker wajah terbaik adalah GR dengan kode Alternatif $\mathrm{A}_{4}$. Berikut adalah hasil penggujian data menggunakan system berbasis web 


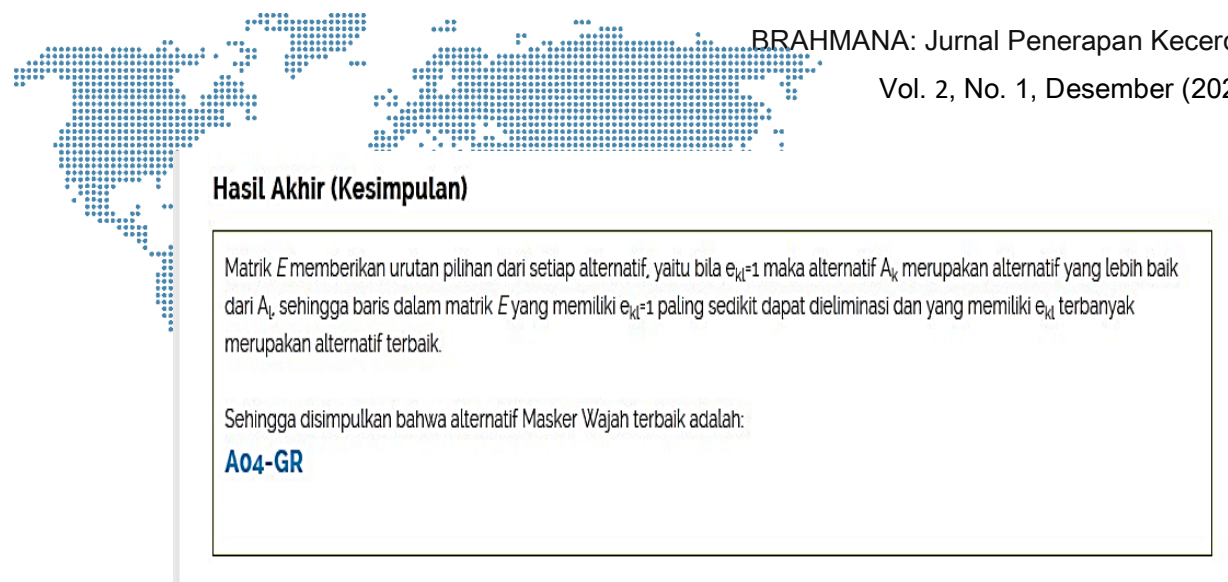

\section{Kesimpulan}

Gambar 1. Kesimpulan

Berdasarkan pembahasan sebelumnya dapat disimpulkan bahwa :

a) Menambah wawasan Sistem Pendukung Keputusan menjadi sarana terbaik bagi wanita Indonesia Kota Pematangsiantar dengan menggunakan algoritma electre.

b) Sumber data penelitian sebagian diambil dari perpustakan sebagai riset" terkait dan selebihnya dari jurnal ilmiah.

c) Sistem Pendukung Keputusan dengan metode Electre dapat di implementasikan kedalam aplikasi berbasis web pada kasus pemilihan masker wajah terbaik untuk mengklasifikasi tingkat kepuasan konsumen terhadap produk dari beberapa toko kecantikan di Pematangsiantar.

d) Hasil akhir dari penyempurnaan matriks dengan alternatife yang tertinggi, sehingga dapat disimpulkan bahwa Alternatif masker wajah terbaik adalah A04GR.

e) Jadi, bahwa metode Electre dapat membantu proses pemilihan masker wajah yang menjadi tingkat perangkingan untuk menjadikan solusi konsumen terhadap jenis produk.

\section{Daftar Pustaka}

[1] Maryani And S. Fachrurrazi, "Sistem Pendukung Keputusan Pemilihan Kosmetik Produk Latulipe Yang Sesuai Dengan Jenis Kulit Wajah Perempuan Indonesia Menggunakan Metode Promethhee," J. Sist. Inf. Issn 2598-599x, Pp. 97-126, 2017.

[2] B. Poernomo, "Sistem Pendukung Keputusan Penerimaan Karyawan Baru Di Departemen Kehakiman Timor - Leste Dengan Menggunakan Metode Saw," Positif, Vol. 3, No. 1, Pp. 10-19, 2017, Doi: 10.31961/Positif.V3i1.397.

[3] M. Sianturi, S. Wulan, Suginam, Rohminatin, And Mesran, "Implementasi Metode Vikor Untuk Menentukan Bahan Kulit Terbaik Dalam Pembuatan Ikat Pinggang," J. Ris. Komput., Vol. 5, No. 1, Pp. 56-60, 2018.

[4] D. R. S. P, A. A. Muin, And M. Amin, "Pemilihan Facial Wash Untuk Kulit Wajah Berminyak Dengan Metode Promethee Ii," Cess, Vol. 4, No. 2, Pp. 222229, 2019.

[5] T. Imandasari, A. Wanto, And A. P. Windarto, "Analisis Pengambilan Keputusan Dalam Menentukan Mahasiswa Pkl Menggunakan Metode Promethee," Vol. 5, No. 3, Pp. 234-239, 2018.

[6] S. R. Ningsih, I. S. Damanik, I. Gunawan, And W. Saputra, "Electre Dalam Menentukan Penerima Program Indonesia Pintar ( Pip ) Melalui Kartu Indonesia Pintar ( Kip ) ( Studi Kasus: Sd Swasta Al - Washliyah Moho Kabupaten Simalungun )," Komik (Konferensi Nas. Teknol. Inf. Dan Komputer), Vol. 1, No. 1, Pp. 264-275, 2017. 